\title{
Kashaya [asp] assimilation and dissimilation by correspondence
}

\author{
Eugene Buckley*
}

\begin{abstract}
An aspirated stop in a Kashaya prefix becomes a plain voiceless stop by dissimilation when the root begins with an aspirate; but it also assimilates to an unaspirated stop in the same position. The OCP cannot help with assimilation, so I propose a unified analysis of the two phenomena within Agreement by Correspondence (Rose \& Walker 2004, Bennett 2013). Unlike somewhat similar cases in the literature with both assimilation and dissimilation, here there is no structural difference. I posit a conjoined constraint that penalizes an initial aspirate in a correspondence relation; the rest follows from standard $\mathrm{ABC}$ assumptions.
\end{abstract}

Keywords. assimilation; dissimilation; aspiration; surface correspondence; Pomoan

1. Introduction. Kashaya is a Pomoan language of the northern California coast. It has dissimilation of the aspiration feature [asp], i.e. $C^{h} \rightarrow C$, before another aspirated consonant $C^{h}$ (with an intervening vowel). This sort of alternation is familiar from Grassmann's Law and similar processes. But Kashaya is noteworthy because it also has assimilation of [asp] before a plain unaspirated $C$ (again with an intervening vowel). This change is a form of nonlocal harmony. What makes the combination of these two processes unusual is that we find the same output from the opposite trigger, and it occurs in exactly the same morphological context. I propose a solution using the formalism of Agreement by Correspondence, which unifies the two phenomena when combined with a conjoined constraint that penalizes a particular configuration of an initial aspirated consonant.

2. Background. The Pomoan family consists of seven languages. Although the basic consonant inventory is similar in most of the languages, and the morphology involved is present in all of them, only Kashaya shows the specific patterns involving aspiration discussed in this paper.

The consonant inventory of Kashaya is shown below (Oswalt 1961, Buckley 1994). Note in particular that there are aspirated and ejective stops corresponding to each plain stop, as well as the affricate $\left[\mathrm{t} \int\right]$ that is conventionally written $c$ and that patterns as a palatal stop. The letter $t$ represents a lamino-dental stop, and $t$ is apico-alveolar.

(1) Kashaya consonant inventory

$\begin{array}{lllllll}\mathrm{p} & \mathrm{t} & \mathrm{t} & \mathrm{c} & \mathrm{k} & \mathrm{q} & \\ \mathrm{p}^{\mathrm{h}} & \mathrm{t}^{\mathrm{h}} & \mathrm{t}^{\mathrm{h}} & \mathrm{c}^{\mathrm{h}} & \mathrm{k}^{\mathrm{h}} & \mathrm{q}^{\mathrm{h}} & \mathrm{h} \\ \mathrm{p} & \mathrm{t}^{\prime} & \stackrel{\mathrm{t}}{ } & \mathrm{c}^{\prime} & \mathrm{k}^{\prime} & \mathrm{q} & \text { ? } \\ \mathrm{b} & & \mathrm{d} & & & & \\ & & \mathrm{s} & \check{\mathrm{s}} & & & \\ & & \mathrm{s} & & & & \\ \mathrm{m} & & \mathrm{n} & & & & \\ \text { w } & & \mathrm{l} & \mathrm{y} & & & \end{array}$

Kashaya has a set of twenty INSTRUMENTAL PREFIXES that attach to around eight hundred verb roots. Most roots occur with only a subset of the prefixes, although some roots can occur with

\footnotetext{
* I would like to thank the audience at the LSA, as well as Will Bennett, for their comments; any errors are my own. Author: Eugene Buckley, University of Pennsylvania (gene@ling.upenn.edu).
} 
any of them. They are all $C V$ in shape, and express the way in which an action was performed or how an event occurred.

(2) Kashaya instrumental prefixes

$\begin{array}{ll}\text { ba- } & \text { with the mouth, by speaking } \\ \text { bi- } & \text { by encircling, by sewing } \\ \text { ca- } & \text { with the rear end; with a knife } \\ \text { cu- } & \text { with a round object; by flowing water } \\ \text { chi- } & \text { by holding part of an object } \\ \text { da- } & \text { with the hand; by waves } \\ \text { di- } & \text { by gravity, by weight } \\ \text { du- } & \text { with the finger } \\ \text { ha- } & \text { with a swinging motion } \\ \text { hi- } & \text { with the body, shoulder } \\ \text { ma- } & \text { with the sole of the foot } \\ \text { mi- } & \text { by kicking; by smelling } \\ \text { mu- } & \text { with heat or energy } \\ \text { p }^{\text {ha- }} & \text { with the end of a long object } \\ \text { p }^{\text {hi- }} & \text { with the side of a long object } \\ \text { p }^{\text {hu- }} & \text { by blowing } \\ \text { qa- } & \text { between forces, with the teeth } \\ \text { si- } & \text { by water, by drinking } \\ \text { ša- } & \text { with a long object moving lengthwise } \\ \text { šu- } & \text { by pulling or pushing }\end{array}$

Among the prefixes containing voiceless stops, three are unaspirated ( $\left.c a^{-}, c u^{-}, q a^{-}\right)$; these never become aspirated. Four are underlyingly aspirated ( $\left.c^{h-}, p^{h} a-, p^{h i-}, p^{h} u-\right)$; these can become unaspirated by the two processes described below in detail. ${ }^{1}$

The examples and statistics in this paper come from a dictionary database in progress. It contains about 17,000 entries, based mainly on a manuscript prepared by Robert Oswalt. The entries include 952 bases (prefix plus root) with an underlyingly aspirated prefix. Among these bases are 513 distinct roots that take at least one of the four aspirated prefixes. There are copious examples of bases containing each prefix: 186 with $c^{h i-}, 196$ with $p^{h} a-, 337$ with $p^{h} i$-, and 233 with $p^{h} u-$.

3. Dissimilation. The dissimilation of [asp] is well described in the literature on Kashaya (Oswalt 1961, Buckley 1994). It takes the basic form shown below, where the first $C^{h}$ is part of an instrumental prefix and the second is initial in the root.

(3) Dissimilation

$$
\mathrm{ChV}^{\mathrm{h}}-\mathrm{C}^{\mathrm{h}} \ldots \rightarrow \mathrm{CV}-\mathrm{C}^{\mathrm{h}} \ldots
$$

This pattern is "robustly attested" crosslinguistically (Bennett 2013), including the famous example of Grassmann's Law in Greek and Sanskrit.

\footnotetext{
${ }^{1}$ There is also a relatively uncommon zero prefix, ignored here; it often carries a passive meaning. Prefixes starting with $/ \mathrm{h} /$ do not undergo loss of aspiration since that would not leave a well-formed consonant. Deletion of the $/ \mathrm{h} /$ is blocked by the strict requirement for an onset in every syllable (Buckley 1994).
} 
In Kashaya, we can see the evidence for underlying aspiration in the four relevant prefixes by noting their form before an ejective, voiced stop, or sonorant. In this context, the aspiration is preserved. $^{2}$

(4) Prefixes with underlying aspiration
a. chi-k'is-
'mark with tool; write'

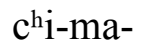
'scoop'
b. $\quad \mathrm{p}^{\mathrm{h}} \mathrm{a}-\mathrm{s}^{\prime} i \mathrm{~m}-$
'fold with end of stick'
'be beyond reach with stick'
c. $\mathrm{p}^{\mathrm{h}} \mathrm{i}-\mathrm{c}$ 'o-
'uncover with hoe'
$\mathrm{p}^{\mathrm{h}} \mathrm{i}-\mathrm{lu} \cdot \mathrm{m}-$
'swat'
d. $\quad p^{h} u-t ’{ }^{\prime} a \cdot \check{s}_{-}$
'blow hair off forehead'
$\mathrm{p}^{\mathrm{h}} \mathrm{u}-\mathrm{wat}{ }^{\mathrm{h}}-$
'weaken by blowing'

In contrast, the same prefixes lack aspiration before an aspirated stop or $/ \mathrm{h} /$.

(5) Loss of aspiration by dissimilation
a. $\quad$ ci-qha ${ }^{\mathrm{h}} \mathrm{m}-$
ci-p ${ }^{\mathrm{h}} \mathrm{u} \cdot-$
'wipe with mop'
b. pa-chi·t-
'stir up dust by dragging'
c. pi-t ${ }^{\text {the}}$ -
pi-thil-
'take out with end of stick'
'search by poking'
d. pu-k ${ }^{\mathrm{h}} \mathrm{et}-$
'spread with edge of stick'
'tear with stick'
'spread apart by blowing'
'be bright as clouds blow away'

This type of dissimilation is traditionally seen as an effect of the Obligatory Contour Principle (OCP), a prohibition on adjacent repetition of a feature. We return to dissimilation below.

4. Assimilation. The assimilation of [asp] is not described in the literature on Kashaya; a few examples are noted but are treated as exceptions. The dictionary data show, however, that it is well attested and regular. In fact, it is comparable in frequency to dissimilation. ${ }^{3}$ The general pattern is as follows.

(6) Assimilation

$\mathrm{ChV}^{\mathrm{h}} \mathrm{C} . . . \rightarrow \mathrm{CV}-\mathrm{C} \ldots$

Notably, in this case the loss of aspiration causes the two consonants to become more similar, although the change in the prefixal consonant is the same in both processes.

The examples in (7) illustrate that aspiration is lost before a plain voiceless stop; that is, the prefixal consonant assimilates in (lack of) aspiration to the root consonant.

(7) Loss of aspiration by assimilation
a. ci-kim-
'catch on something'
ci-pe $\cdot 1-$
'spread with tool'

\footnotetext{
${ }_{3}^{2}$ Following the traditional orthography, long vowels are notated with $[\cdot]$ rather than a colon.

${ }^{3}$ Specifically, there are 67 examples of assimilation in underlying $C^{h} V-C V \ldots$ and 72 examples of dissimilation in $C^{h} V-C^{h} V \ldots$, in both cases involving all four prefixes. These numbers exclude roots with laryngeal increments, discussed below in section 8 .
} 

b. pa-co-
'crush with pestle'
pa-ți-
c. pi-ku't-
'make pounding noise'
pi-tul-
'knock off with stick'
'straighten with hammer'
d. pu-pa-
$\mathrm{pu}-\mathrm{ta} \cdot \mathrm{m}-$
'(wind) cover with debris'
'wind make hammering noise'

For completeness, note that plain prefixes never become aspirated, regardless of the following consonant, so the assimilation is only in one direction.

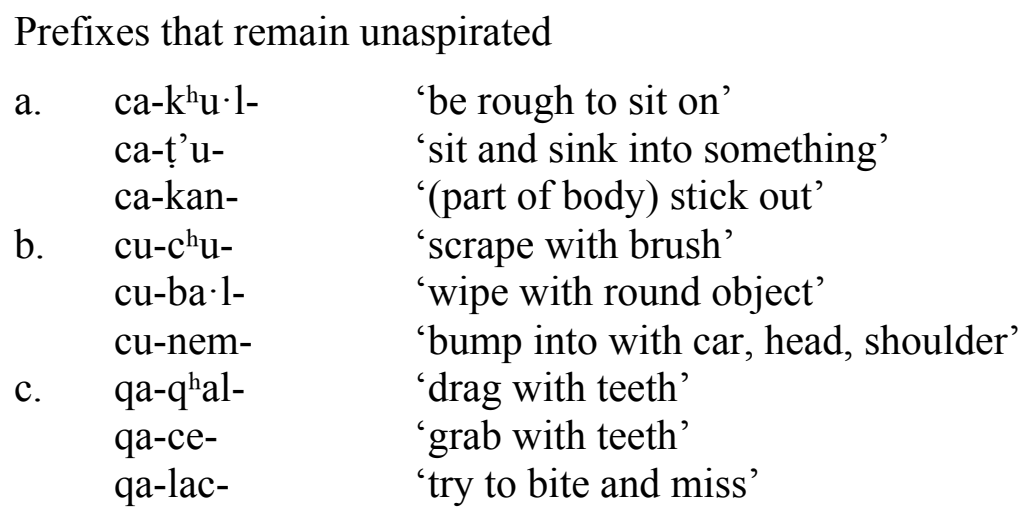

One could simply treat the two processes as distinct, or delete aspiration more arbitrarily before non-ejective voiceless stops. The goal of this paper, however, is to provide a unified account of these facts as the interaction of [asp] features under a single theoretical framework.

5. Assimilation as harmony. Kashaya assimilation is formally quite similar to what is usually described as nonlocal harmony, perhaps best known from Chumash in which the coronal sibilants [s] and [S] agree throughout out a word (McCarthy 2007). Such nonlocal harmony is also attested with laryngeal features, however, as in Zulu roots where stops agree in voicing and aspiration (Khumalo 1987, Hansson 2001); since it is internal to roots, this pattern does not cause alternations, but it is enforced in loanword adaptation.

A crucial observation about the Kashaya alternation is that it occurs only when it will yield a $C V$ - prefix - not, of course, when it would yield $C^{h} V-C^{h} V \ldots$, since that is exactly what dissimilation eliminates in the same morphological context. The traditional use of the OCP for dissimilation is of no help here, since it is an entirely different featural interaction. Superficially what we observe is the opposite of dissimilation, yet the two processes yield the same result in the prefix itself. I therefore consider a shared mechanism for both: surface correspondence in an Optimality Theory approach.

One means of formalizing assimilation between similar segments is Agreement by Correspondence (Rose \& Walker 2004, Hansson 2001). In Kashaya these are voiceless, nonglottalized stops that share their value for [asp]. The ABC theory establishes a correspondence or CORR surface relation between similar segments; this sets up the locus of agreement. Constraints that establish the CORR relation are ranked by degree of similarity. For example, the strictest identity would involve stops with the same place of articulation and same value for aspiration, CORR-T $\leftrightarrow$ T. Shared place is irrelevant in the Kashaya pattern, so we look to broader constraints that operate between stops with a potentially different place of articulation: if they have the same aspiration, CORR- $\mathrm{K}^{\mathrm{h}} \leftrightarrow \mathrm{T}^{\mathrm{h}}$, or different aspiration, CORR- $\mathrm{K}^{\mathrm{h}} \leftrightarrow \mathrm{T}$. 
Identity among segments that stand in correspondence is enforced by a CC IDENT constraint specific to a feature. For Kashaya, this is CC.IDENT-[asp], which requires that consonants in correspondence agree in [asp]. It operates on the output representation and is not relevant without satisfaction of a CORR constraint that sets up the correspondence relation. Note that it is crucially different from plain IDENT, more explicitly IO-IDENT, which refers to input-output faithfulness and will be violated if assimilation (or dissimilation) occurs.

To generate assimilation, similar stops must be in correspondence due to CORR (9a); sets of such consonants are shown in curly braces for each candidate. Segments in correspondence must be identical for [asp], due to CC.IDENT (b). More specific IDENT-RT privileges faithfulness to segments in the root morpheme so that the change occurs in the prefix (c).

(9) Tableau for assimilation

\begin{tabular}{|c|c|c|c|c|c|}
\hline$/ \mathrm{p}^{\mathrm{h}} \mathrm{a}-\mathrm{tul} /$ & $\begin{array}{c}\text { IDENT-RT- } \\
\text { [asp] }\end{array}$ & $\begin{array}{c}\mathrm{CC} \cdot \mathrm{IDENT}- \\
\text { [asp] }\end{array}$ & $\begin{array}{l}\text { CORR- } \\
\mathrm{K}^{\mathrm{h}} \leftrightarrow \mathrm{T}^{\mathrm{h}}\end{array}$ & $\begin{array}{l}\text { CORR- } \\
\mathrm{K}^{\mathrm{h} \leftrightarrow \mathrm{T}}\end{array}$ & $\begin{array}{l}\text { IDENT- } \\
\text { [asp] }\end{array}$ \\
\hline $\begin{array}{cc}\text { a. } & \mathbf{p}^{\mathbf{h}} \mathbf{a}-\mathbf{t u l} \\
& \{-\}\end{array}$ & & & & $* !$ & \\
\hline $\begin{array}{cc}\text { b. } & \mathbf{p}^{\mathrm{h}} \mathbf{a}-\mathbf{t u l} \\
& \left\{\mathrm{p}^{\mathrm{h}} \mathrm{t}\right\}\end{array}$ & & $* !$ & & & \\
\hline $\begin{array}{cc}\text { c. } & \mathbf{p}^{\mathrm{h}} \mathbf{a}-\mathbf{t}^{\mathrm{h}} \mathbf{u l} \\
& \left\{\mathrm{p}^{\mathrm{h}} \mathrm{t}^{\mathrm{h}}\right\} \\
\end{array}$ & $* !$ & & & & $*$ \\
\hline $\begin{array}{c}\text { pa-tul } \\
\{\mathrm{p} \mathrm{t}\}\end{array}$ & & & & & $*$ \\
\hline
\end{tabular}

6. Analysis of dissimilation. A reason that the $\mathrm{ABC}$ theory is especially promising for Kashaya is that it can also be used to generate dissimilation (Bennett 2013, 2015, Bennett \& Rose 2016, Ozburn \& Kochetov 2013). In analyzing dissimilation, correspondence across some boundary is penalized by a CC EDGE constraint; in the present case, it is the prefix-root boundary, but for other languages a prosodic edge such as the syllable can be used for morpheme-internal dissimilation. That conflicts with the CORR requirement if segments are similar; the central mechanism is that dissimilation reduces the segment similarity to resolve the conflict. Notably there is no role for the OCP in this scenario.

As a first pass, the basic approach to Kashaya dissimilation is that similar stops should be in correspondence (10a). But correspondence is penalized across the prefix boundary (b), so stops in that position are made less similar by deleting [asp] (c).

(10) Tableau for dissimilation (preliminary)

\begin{tabular}{|c|c|c|c|c|c|}
\hline$/ \mathrm{p}^{\mathrm{h}} \mathrm{a}-\mathrm{t}^{\mathrm{h}} \mathrm{il} /$ & $\begin{array}{c}\text { CC.IDENT- } \\
\text { [asp] }\end{array}$ & $\mathrm{CC} \cdot \mathrm{EDGE}$ & $\begin{array}{l}\text { CORR- } \\
\mathrm{K}^{\mathrm{h}} \leftrightarrow \mathrm{T}^{\mathrm{h}}\end{array}$ & $\begin{array}{l}\text { CORR- } \\
\mathrm{K}^{\mathrm{h} \leftrightarrow \mathrm{T}}\end{array}$ & $\begin{array}{l}\text { IDENT- } \\
\text { [asp] }\end{array}$ \\
\hline $\begin{array}{cc}\text { a. } & \mathbf{p}^{\text {h }} \mathbf{a}-\mathbf{t}^{\text {hil }} \\
& \{-\}\end{array}$ & & & $* !$ & $*$ & \\
\hline $\begin{array}{rr}\text { b. } & \mathbf{p}^{\mathrm{h}} \mathbf{a}-\mathbf{t}^{\mathrm{h}} \mathbf{i l} \\
& \left\{\mathrm{p}^{\mathrm{h}} \mathrm{t}^{\mathrm{h}}\right\} \\
\end{array}$ & & $* !$ & & & \\
\hline $\begin{array}{c}\text { c. } \\
\text { pa-thil } \\
\{-\}\end{array}$ & & & & $*$ & $*$ \\
\hline
\end{tabular}

Note that the constraint in the position of CC.EDGE here will be modified below in (11). 
The tableau in (10) shows how dissimilation would generally be treated. In contrast, for assimilation in a sequence such as $/ \mathrm{p}^{\mathrm{h}} \ldots \mathrm{t} /$, we must assume CoRR between stops that differ in [asp] by means of CORR-K $\mathrm{K}_{\leftrightarrow} \leftrightarrow \mathrm{T}$, plus IDENT-CC[asp] that actually causes assimilation. By implication, more-similar $/ \mathrm{p}^{\mathrm{h}} \ldots \mathrm{t}^{\mathrm{h}}$ is subject to a higher-ranked constraint; in other words, CORR$\mathrm{K}^{\mathrm{h}} \leftrightarrow \mathrm{T}^{\mathrm{h}}>>$ CORR- $\mathrm{K}^{\mathrm{h}} \leftrightarrow \mathrm{T}$. But for dissimilation to happen, that higher-ranked CORR- $\mathrm{K}^{\mathrm{h}} \leftrightarrow \mathrm{T}^{\mathrm{h}}$ must be blocked, since otherwise it would force the maintaining of [asp] identity. The challenge of Kashaya is that existing analyses use $\mathrm{CC} \cdot$ EDGE to bring about dissimilation, and those languages have no correspondence across the Stem boundary. But in Kashaya, this incorrectly prevents assimilation in the same context; the prefix-root structure is identical for both dissimilation and assimilation. The only difference is phonological, the presence or absence of [asp] on the rootinitial consonant. There must be something extra in Kashaya that limits the scope of CC.EDGE to the context where dissimilation actually occurs.

7. Unified treatment. As we have seen, dissimilation, $C^{h} V-C^{h} \rightarrow C V-C^{h}$, yields the same pairing targeted by assimilation, $C^{h} V-C \rightarrow C V-C$, just in a different order. To handle both processes by $\mathrm{ABC}$, we must specifically penalize the CORR relation when the prefix has [asp]. Deaspiration of a prefix happens in two different ways: assimilation of $C^{h} V-C$ to $C V-C$ follows the pressure of CC.IDENT, whereas dissimilation of $C^{h} V-C^{h}$ to $C V-C^{h}$ makes them more dissimilar so that correspondence is avoided. What they share is avoidance of [asp] in a prefix, which can be captured by a constraint that disfavors exactly that configuration: ${ }^{*} \mathrm{PREF} /[\mathrm{asp}]{ }^{4}{ }^{4}$ This is consistent with the widespread observation that affixes tend to permit fewer marked structures than roots; it can be compared to a constraint that is not violated in Kashaya, *PREF/[gl], which expresses the lack of any ejectives in the set of prefixes. Other unmarked aspects of Kashaya instrumental prefixes are that all have the core syllable shape $C V$ and contain just the peripheral vowels $/ \mathrm{i} \mathrm{u} \mathrm{a/,}$ not $/ \mathrm{e} \mathrm{o} / .^{5}$

*PREF/[asp] has a limited effect, showing its presence only in the interaction of assimilation and dissimilation. In order to capture this limitation, I make use of local constraint conjunction (Crowhurst 2011). This additional power is necessary because in other dissimilation analyses, $\mathrm{CC} \cdot$ EDGE is sufficient by itself, since no assimilation occurs across the prefix-root boundary. In Kashaya, however, we need to selectively block assimilation; it cannot result in two [asp] consonants. A conjunction of CC.EDGE-(Stem) with *PREF/[asp] penalizes a CORR relation across the prefix-root boundary if there is also aspiration in the prefix; the locus of joint violation is the initial $C$ of the prefix, since it bears prefixal [asp] and participates in a $C C$ relation across the boundary. Loss of [asp] reduces pressure for CORR, i.e. dissimilation satisfies the conjoined constraint; but since an assimilated configuration lacks [asp] in the prefix, it does not violate the conjoined constraint, and there is no need for dissimilation.

\footnotetext{
${ }^{4}$ Another possible approach is a ranking of more general constraints, IDENT-RoOT $>$ *[asp] $>$ IDENT-AFFIX, but this depends on the analysis of suffixal aspiration, which occurs in the negative suffix $-t^{h}$ and surfaces faithfully. For simplicity I maintain here the more direct constraint on prefixes.

${ }^{5}$ The instrumental prefixes are the only common prefixes in the language; one infrequent plural pattern consists of $l V$ - in which the vowel is copied from the following root syllable. Buckley (1994) treats the voiced stops [b d] as derived from underlying glottalized /m' n'/ in onset position, and these occur in prefixes, but since the segments surface without the $[\mathrm{gl}]$ feature they satisfy the $* \mathrm{PREF} /[\mathrm{gl}]$ constraint. Prefixes containing $/ \mathrm{u} /$ surface with $[\mathrm{o}]$ when the following root syllable contains /o/, but the constraint enforcing this harmony would simply be ranked higher than the markedness constraint against mid vowels in prefixes.
} 
As shown in the next tableau, similar stops should be in correspondence (11a), but correspondence is penalized with [asp] across the prefix boundary (b). As a result, stops are made less similar by deleting [asp] (c).

(11) Tableau for dissimilation (revised)

\begin{tabular}{|c|c|c|c|c|c|c|}
\hline$/ \mathrm{p}^{\mathrm{h}} \mathrm{a}-\mathrm{t}^{\mathrm{h}} \mathrm{il} /$ & $\begin{array}{c}\mathrm{CC} \cdot \text { IDENT- } \\
\text { [asp] }\end{array}$ & $\begin{array}{l}* \mathrm{PREF} /[\mathrm{ASP}] \\
\& \mathrm{CC} \cdot \mathrm{EDGE}\end{array}$ & $\begin{array}{l}\text { CORR- } \\
\mathrm{K}^{\mathrm{h}} \leftrightarrow \mathrm{T}^{\mathrm{h}}\end{array}$ & $\begin{array}{l}\text { CORR- } \\
\mathrm{K}^{\mathrm{h}} \leftrightarrow \mathrm{T}\end{array}$ & $\mathrm{CC} \cdot \mathrm{EDGE}$ & $\begin{array}{c}\text { IDENT- } \\
\text { [asp] }\end{array}$ \\
\hline a. $\begin{array}{c}\mathbf{p}^{\mathbf{h}} \mathbf{a}-\mathbf{t}^{\mathbf{h}} \mathbf{i l} \\
\{-\}\end{array}$ & & & $* !$ & $*$ & & \\
\hline $\begin{array}{r}\text { b. } \mathbf{p}^{\mathrm{h}} \mathbf{a}-\mathbf{t}^{\mathrm{h}} \mathbf{i l} \\
\left\{\mathrm{p}^{\mathrm{h}} \mathrm{t}^{\mathrm{h}}\right\}\end{array}$ & & $* !$ & & & $*$ & \\
\hline $\begin{array}{c}\text { c. pa-thil } \\
\{-\}\end{array}$ & & & & $*$ & & $*$ \\
\hline $\begin{array}{r}\text { d. } \mathbf{p a}^{\mathbf{a}^{\mathrm{h}} \mathbf{i l}} \\
\left\{\mathrm{p} \mathrm{t}^{\mathrm{h}}\right\}\end{array}$ & $* !$ & & & & $*$ & $*$ \\
\hline
\end{tabular}

There is no assimilation for plain prefixes, as shown in (12). Matching plain $C$...C is prevented by Root faithfulness (b). Matching $C^{h} \ldots C^{h}$ would be a dissimilation context, and is prevented by the same conjoined constraint, not by the OCP $(\mathrm{d})$.

(12) Tableau for unaspirated prefix

\begin{tabular}{|c|c|c|c|c|c|c|}
\hline$/ \mathrm{ca}-\mathrm{k}^{\mathrm{h}} \mathrm{u} \cdot \mathrm{l} /$ & $\begin{array}{l}\text { IDENT-RT } \\
\text { [asp] }\end{array}$ & $\begin{array}{l}\text { CC } \cdot \text { IDENT- } \\
{[\text { asp] }}\end{array}$ & $\begin{array}{l}* \mathrm{PREF} /[\mathrm{ASP}] \\
\& \mathrm{CC} \cdot \mathrm{EDGE}\end{array}$ & $\begin{array}{l}\text { CORR- } \\
\mathrm{K}^{\mathrm{h}} \leftrightarrow \mathrm{T}^{\mathrm{h}}\end{array}$ & $\begin{array}{l}\text { CORR- } \\
\mathrm{K}^{\mathrm{h}} \leftrightarrow \mathrm{T}\end{array}$ & $\mathrm{CC} \cdot \mathrm{EDGE}$ \\
\hline $\begin{array}{c}\text { ca-k } \mathbf{k}^{\mathbf{h}} \mathbf{u} \cdot \mathbf{l} \\
\{-\}\end{array}$ & & & & & $*$ & \\
\hline $\begin{array}{c}\text { b. ca-ku·l } \\
\{\mathrm{c} \mathrm{k}\}\end{array}$ & $* !$ & & & & & $*$ \\
\hline 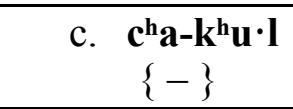 & & & & $* !$ & $*$ & \\
\hline $\begin{array}{cc}\text { d. } & \mathbf{c}^{\mathrm{h}} \mathbf{a}-\mathbf{k}^{\mathrm{h}} \mathbf{u} \cdot \mathbf{l} \\
& \left\{\mathrm{c}^{\mathrm{h}} \mathrm{k}^{\mathrm{h}}\right\} \\
\end{array}$ & & & $* !$ & & & $*$ \\
\hline
\end{tabular}

No untriggered loss of aspiration occurs, of course. Other consonants have no correspondence relation, because the consonants are too dissimilar; more specifically, CoRR-K $\mathrm{K}^{\mathrm{h}} \leftrightarrow \mathrm{D}$ (not shown) is ranked below IDENT-[asp]. Loss of aspiration is otherwise prevented by simple input-output faithfulness (13c) that applies to affixes as well as roots. 
Tableau for root with voiced stop

\begin{tabular}{|c|c|c|c|c|c|c|}
\hline$/ p^{\mathrm{h}} \mathrm{a}-\mathrm{dul} /$ & $\begin{array}{l}\text { CC.IDENT- } \\
\text { [asp] }\end{array}$ & $\begin{array}{l}* \text { PREF/[ASP] } \\
\& \text { CC.EDGE }\end{array}$ & $\begin{array}{l}\text { CORR- } \\
\mathrm{K}^{\mathrm{h} \leftrightarrow \mathrm{T}^{\mathrm{h}}}\end{array}$ & $\begin{array}{l}\text { CORR- } \\
\mathrm{K}^{\mathrm{h}_{\leftrightarrow}} \mathrm{T}\end{array}$ & $\mathrm{CC} \cdot$ EDGE & $\begin{array}{l}\text { IDENT- } \\
\text { [asp] }\end{array}$ \\
\hline \multicolumn{7}{|l|}{$\begin{array}{c}\text { a. } \\
\{-\}\end{array}$} \\
\hline $\begin{array}{c}\text { b. } \mathbf{p}^{\text {haa-dul }} \\
\left\{\mathbf{p}^{\text {h }} \mathrm{d}\right\}\end{array}$ & $* !$ & $*$ & & & $*$ & \\
\hline $\begin{array}{c}\text { c. pa-dul } \\
\{-\}\end{array}$ & & & & & & *! \\
\hline $\begin{array}{l}\text { d. pa-dul } \\
\{\mathrm{pd}\}\end{array}$ & & & & & $* !$ & $*$ \\
\hline
\end{tabular}

A full ranking of the constraints mentioned here is shown in (14).

(14) Overall constraint ranking

IO-IDENT-RT-[asp] $>>$ CC IDENT-[asp] $>>$ *PREF/[ASP] \& CC $\cdot$ EDGE $>>$ CORR-K $\mathrm{K}^{\mathrm{h}} \leftrightarrow \mathrm{T}^{\mathrm{h}}>>$ CORR-K ${ }^{\mathrm{h}} \leftrightarrow \mathrm{T}>>$ CC.EDGE $>>$ IO-IDENT-[asp] $>$ CORR-K $\mathrm{K}^{\mathrm{h}} \leftrightarrow \mathrm{D}$

This unified analysis using surface correspondence permits treating assimilation and dissimilation in one framework, rather than two entirely different methods, such as the OCP plus some kind of agreement or spreading that would yield the same result for the prefix by coincidence. Given that this combination of processes is rather unusual, we might ask how it came about. Neither process is found in the other Pomoan languages, so it appears to be entirely innovative in Kashaya. I turn now to a somewhat speculative answer.

8. Laryngeal increments. In the Pomoan languages generally, as well as in several other families of the region, there are frequently glottal segments $h$ or ? featurally tied to a following $C$ (Oswalt 1998). These LARYNGEAL (or GLOTTAL) INCREMENTS behave in some ways like a single segment with the following consonant, but ultimately syllabify as two segments, with the increment in the coda and the $C$ in the following onset. In Kashaya, the restrictions are as follows (Buckley 1994). Aspirated $C^{h}$ takes $h$ to form $h C^{h}$ so the laryngeal feature [asp] matches. Ejective $C^{\prime}$ takes ? to form ? $C^{\prime}$ (including also [b d], which behave as if glottalized /m' n'/). Either increment can occur before sonorants, which have no laryngeal specification; but $h$ is twice as common. Plain voiceless $C$ overwhelmingly takes $h$.

An important aspect of increments in Kashaya is termed the DECREMENT by Oswalt (1961). In this process, an increment is deleted in certain morphological contexts, such as the pluractional form of verbs, which has various allomorphs (often a suffix involving /t/). It does not cause any change in the laryngeal features of the main root-initial consonant.

(15) Loss of laryngeal increment in plural form of verb
a. da-hcha-
'knock over with hand'
da-cha-t-
'knock over several with hand'
b. $\quad \mathrm{p}^{\mathrm{h}} \mathrm{i}-\mathrm{Pc}$ 'on-
'detach with stick'
$\mathrm{p}^{\mathrm{h}} \mathrm{i}$-c'on-ta-
'detach several with stick'
c. du-htay-
'touch with finger'
du-tay-?ta-
'touch several times with finger' 
$\begin{array}{ll}\text { d. ma-Pya- } & \text { 'almost smash with foot' } \\ \text { ma-ya-t- } & \text { 'almost smash several with foot' }\end{array}$

Since one variety of the increment is $/ \mathrm{h} /$, it interacts with the aspiration of a prefix. We find a uniform unaspirated prefix before $/ \mathrm{h} /$ that occurs with an aspirated stop, since there is a trigger for dissimilation with or without the increment (16a); a non-uniform prefix before $/ \mathrm{h} / \mathrm{with}$ a sonorant, since only the increment can cause dissimilation (b); and a uniformly unaspirated prefix with $/ \mathrm{h}$ / before a plain stop, though here it is a combination of dissimilation and assimilation that yields the deaspiration (c).

(16) Prefix aspiration with laryngeal increment alternations
a. pu-hcha-
'blow over'
pu-cha-t-
'blow several over'
b. pi-hye-
'stop chopping'
$\mathrm{p}^{\mathrm{h}}$ i-ye-t-
'stop chopping several'
c. ci-htay-
'touch with tool'
ci-tay-?ta-
'touch several times with tool'

The interesting case is (c), and it may have served historically as the basis for the development of deaspiration by assimilation.

Prefixal aspiration is always uniform in the context of root-initial aspirated stops (with $/ \mathrm{h} /$ ) and glottalized and voiced stops (with $/ \mathrm{R} /$ ); that is, for transparent phonological reasons, the prefixes are consistently $C^{h} V$ - or $C V$-regardless of whether the increment is present. One could imagine a different grammar in which dissimilation of aspiration occurred before the loss of an increment, in counterbleeding order, so that the prefix on a particular root was always the same in surface form; but pairs as in (16b) show that this is not the case in Kashaya, leading to a lack of paradigm uniformity. In (16c), however, we do find a uniform prefix. Suppose that plain stops originally did not cause assimilation, so the aspiration in the prefix would be inconsistent, as with sonorants. Yet the other stops have consistent prefixes. Roots with $/ \mathrm{ht} /$ were deaspirated, as with $/ \mathrm{ht} \mathrm{h} /$, but decremented $/ \mathrm{t} /$ came to pattern with $/ \mathrm{t} / \mathrm{h}$. This is not simple paradigm uniformity, since (for example) $/ \mathrm{hn} /$ decremented to $/ \mathrm{n} /$ did not undergo the same adjustment.

Why did just plain stops undergo this apparent shift? For one thing, membership in the larger class of obstruents may have set the stage for the reanalysis. But beyond that, the distribution of increments is quite different for plain stops and sonorants. Very roughly, about half of potential increment-bearing consonants have one. Among these, although sonorants show a modest preference for $/ \mathrm{h} /$ over $/ \mathrm{P} /$ of around 2 to 1 , for plain stops the preference is more than 10 to 1.6

(17) Frequency of laryngeal increments by class of root consonant

\begin{tabular}{|c|c|c|c|c|c|c|c|c|c|c|c|c|}
\hline & \multicolumn{2}{|c|}{ Aspirated } & \multicolumn{2}{|c|}{ Plain } & \multicolumn{2}{|c|}{ Fricative } & \multicolumn{2}{|c|}{ Ejective } & \multicolumn{2}{|c|}{ Voiced } & \multicolumn{2}{|c|}{ Sonorant } \\
\hline$/ \mathrm{h} /$ & 78 & $50.0 \%$ & 92 & $49.5 \%$ & 45 & $57.0 \%$ & 1 & $0.4 \%$ & $\mathbf{0}$ & $0.0 \%$ & 47 & $30.5 \%$ \\
\hline /P/ & 7 & & 8 & & 1 & & & & 32 & & 4 & \\
\hline hone & 71 & $45.5 \%$ & 86 & $46.2 \%$ & 33 & $41.8 \%$ & 130 & $50.8 \%$ & 29 & $47.5 \%$ & 83 & $53.9 \%$ \\
\hline
\end{tabular}

\footnotetext{
${ }^{6}$ Notice that fricatives also show a near absolute association with $/ \mathrm{h} /$ rather than $/ \mathrm{l} /$. These cannot be taken as evidence for plain obstruents more generally, however, because it is possible that the voiceless fricatives of Kashaya (there are no voiced fricatives) actually pattern as [asp] in the first place (Buckley 1994).
} 
Given this asymmetric distribution, extending deaspiration to contexts before plain stops, with or without an increment, would yield uniform paradigms more than $90 \%$ of the time. Clearly it is not just a matter of uniformity, however, since close to half the roots with an initial plain stop do not have an increment at all, and these also undergo deaspiration by assimilation.

There are eight roots that have plain stops with a glottal stop increment (in all cases / $\mathrm{pt} /$ ), and these suggest a further paradigm uniformity: most of the aspirated prefixes are recorded as unaspirated, as though the / $\mathrm{P} /$ were transparent to assimilation. At least one of them has a plural form without the increment, i.e. /Pțaš/ becomes plural /țaš/, where the increment does not interfere with assimilation.

$$
\begin{aligned}
& \text { Glottal increment with plain stop } \\
& \begin{array}{ll}
\text { pi-Pțaš- } & \text { 'beat all with side of long object' } \\
\text { pa-Pțim- } & \text { 'barely stand' } \\
\text { ci-Pțu- } & \text { 'be on edge by holding handle' }
\end{array}
\end{aligned}
$$

Similar are instances of $/ \mathrm{R} /$ preceding an aspirated consonant, which violate the general correlation of [asp] between the increment and the following consonant. In these cases, they may not be true increments but rather ordinary clusters, which do occasionally occur in root-initial position; for instance, the plural of $/ \mathrm{Pc}^{\mathrm{h}} \mathrm{a} /$ is $/ \mathrm{R}^{\mathrm{h}} \mathrm{a}-\mathrm{t} /$ even though this plural suffix normally triggers the decrement. Nevertheless, the glottal stop does not block dissimilation.

(19) Glottal increment with aspirated stop

$$
\begin{array}{ll}
\text { pi-?cha- } & \text { 'head snap forward and stop suddenly' } \\
\text { pa-Pk'oš- } & \text { 'bend knee' }
\end{array}
$$

I do not attempt to develop a synchronic analysis of this apparent transparency, however, since the data are rather sparse and not entirely consistent. Not only is the number of such roots small, but many are poorly attested in the corpus.

9. Conclusion. I have shown that Kashaya has deaspiration in prefixes not only by dissimilation from a following aspirated consonant, but also by assimilation to a following plain stop. I have further argued that Agreement by Correspondence, along with a conjoined constraint on aspirated prefix consonants, can unify these two processes in one theoretical approach.

There are two alternatives to the unified ABC approach. The first is to assume formally distinct processes that happen to result in the same outcome for the prefix, such as dissimilation by the OCP and spreading or another agreement process to accomplish assimilation. This generates the facts, but makes no connection between what certainly appear to be related processes. The second is to abandon the assumption that the processes involve interactions of [asp] values in the prefix and root, for example by stipulating the deletion of [asp] before nonglottalized stops that may or may not be aspirated. This too generates the facts, and by a single rule or constraint, but makes no formal connection to crosslinguistic processes of dissimilation and assimilation.

Based on the patterning of laryngeal increments, I have suggested that alternations like -htay- -tay-were the seed of the assimilatory deaspiration; since the prefix underwent deaspiration before the increment, it maintained this form even in the absence of the increment, such as in the pluractional form of the verb. Although uniform realization of the prefix with a particular root may have played a role historically, this is clearly not the core aspect of the resulting system; deaspiration was extended to roots with plain stops like -tul-, which is 
never -htul-, and not to roots like -hye-- $-y e-$, which remains non-uniform because it lacks a plain stop.

Suitably, only plain stops are susceptible to the assimilation analysis suggested here. Sonorants are utterly different from aspirated stops, but $/ \mathrm{t} /$ and $/ \mathrm{t}^{\mathrm{h}} / \mathrm{differ}$ in just one feature. This created an opening for learners to reanalyze the pattern based on featural similarity. The close relation between $T$ and $T^{h}$ likely played a crucial role in the diachronic development of the pattern, thereby supporting the central role played by the same similarity in the synchronic analysis proposed here.

\section{References}

Baković, Eric. 2000. Harmony, dominance, and control. New Brunswick, NJ: Rutgers University dissertation.

Bennett, William G. 2013. Harmony, dissimilation, and correspondence. New Brunswick, NJ: Rutgers University dissertation.

Bennett, William G. 2015. Assimilation, dissimilation, and surface correspondence in Sundanese. Natural Language and Linguistic Theory 33. 371-415. http://dx.doi.org/10.1007/s11049-014-9268-2.

Bennett, William G. \& Sharon Rose. 2016. Correspondence and Moro [-voice] dissimilation. Ms., Rhodes University \& University of California, San Diego.

Buckley, Eugene. 1994. Theoretical aspects of Kashaya phonology and morphology. Stanford, CA: Center for the Study of Language and Information.

Crowhurst, Megan J. 2011. Constraint conjunction. In Marc van Oostendorp, Colin J. Ewen, Elizabeth Hume \& Keren Rice (eds.), The Blackwell companion to phonology. Chapter 62. Malden, MA: WileyBlackwell.

Hansson, Gunnar. 2001. Theoretical and typological issues in consonant harmony. Berkeley, CA: University of California dissertation.

Khumalo, James Steven Mzilikazi. 1987. An autosegmental account of Zulu phonology. Johannesburg: University of the Witwatersrand dissertation.

McCarthy, John. 2007. Consonant harmony via correspondence: Evidence from Chumash. $\mathrm{Pa}$ pers in Optimality Theory III (University of Massachusetts Occasional Papers in Linguistics). 31.

McCarthy, John \& Alan Prince. 1995. Faithfulness and reduplicative identity. Papers in Optimality Theory (University of Massachusetts Occasional Papers in Linguistics) 18. 249-384.

Oswalt, Robert L. 1961. A Kashaya grammar (Southwestern Pomo). Berkeley, CA: University of California dissertation.

Oswalt, Robert L. 1998. Three laryngeal increments of Kashaya. In Leanne Hinton \& Pamela Munro (eds.), Studies in American Indian languages: description and theory. 87-94. Berkeley, CA: University of California Press.

Ozburn, Avery \& Alexei Kochetov. 2013. Lezgian laryngeal harmony alternations. Poster presented at Phonology 2013, University of Massachusetts.

Rose, Sharon \& Rachel Walker. 2004. A typology of consonant agreement as correspondence. Language 80. 475-531. http://dx.doi.org/10.1353/lan.2004.0144. 